\title{
Les enseignants, les arts et la culture : une connivence possible?
}

\section{HRONIQUE • Formation des maîtres}

Dans une édition récente du magazine Le Point, celle du 23 mai 2017, les résultats d'une enquête conduite par l'IFOP pour le groupe de réflexion Valeur(s) Cultures sur les « envies culturelles des Français » - et dont on peut penser queles « envies culturelles » des Québécois ne sont pas très différentes - rapportent, entre autres choses, que « pour une part importante de Français, entre un quart et la moitié d'entre eux, et de façon plus importante encore dans les classes populaires selon les activités culturelles concernées, ce n'est pas le manque de temps ou d'argent qui les empêche de visiter une exposition, d'aller au théâtre ou de lire un livre, mais le manque d'envie ». Panne du désir! Alors que la culture est accessible, n’a jamais été aussi accessible, elle ne semble plus désirable. Résultat pour le moins troublant qui interroge autant les politiques culturelles, généralement centrées sur l'offre de culture, que la demande et les publics de culture, et qui reconduit le constat maintes fois répété par les sociologues de la culture et de l'éducation : l'appropriation de la culture et les pratiques culturelles demeurent socialement différenciées et donc inégalitaires. Dur constat pour une société qui partage le projet d'une éducation artistique et culturelle pleinement démocratique. Deux questions surgissent : comment rendre pour chacune et chacun l'art et la culture désirable et praticable? L'école peut-elle jouer un rôle significatif à cet égard? Peut-elle redonner ou donner le goût et le désir de l'art et de la culture? Pour esquisser quelques éléments de réponse à ces questions, je propose d'examiner deux ensembles de considérations. Le premier ensemble a trait au rôle et à la place de la pratique et de l'éducation artistiques à l'école. Le deuxième portera sur les futurs enseignants ${ }^{1}$. 


\section{Place et rôle de la pratique et de l'éducation artistiques à l'école}

Je touche ici à une question qui n'est pas exempte de tensions et de contradictions, voire de paradoxes. Nombreux sont d'avis qu'une éducation artistique à l'école constitue l'un des piliers d'une participation culturelle tout au long de la vie. Or, si nous excluons toutes les écoles à vocation particulière et toutes celles qui offrent des programmes particuliers en arts-études, il faut reconnaître que l'éducation et la pratique artistiques à l'école occupent une place pour le moins modeste pour ne pas dire marginale. Plusieurs faits l'attestent. La place dévolue aux arts dans le régime pédagogique est relativement mineure et ne cesse de s'atténuer au fil de la scolarisation. Plus on avance dans son parcours scolaire et moins on se trouve en contact avec les arts. Non seulement cette place est-elle timide, mais elle est aussi régulièrement menacée chaque fois que le programme d'études fait l'objet de réaménagements. Par rapport aux disciplines scolaires qui comptent, et dans un contexte où domine la préoccupation économique, l'éducation et la pratique artistiques semblent de peu de poids. En outre, les aménagements physiques pour les enseignements artistiques sont souvent inadéquats, plus souvent d'ailleurs au primaire qu'au secondaire, et la formation en arts des futurs enseignantes et enseignants du primaire est pour ainsi dire minimale. Qui pourrait soutenir que ce sont là des conditions favorables à une véritable éducation et à une pratique artistiques à l'école?

Paradoxalement, au moment où l'éducation aux arts occupe une place ténue dans la formation de l'élève, on constate que les attentes sont souvent élevées à l'égard de l'art et de la culture à l'école. Aujourd'hui, le recours à l'art a le dos large... très large! On espère de l'art la réussite scolaire, le rétablissement du lien social, la formation du citoyen, l'épanouissement individuel, la lutte contre l'échec et le décrochage scolaire, l'atténuation de la violence et de l'intolérance, et j'en passe. Les dispositifs d'éducation artistique sont en outre soumis à l'exigence d'évaluation, à la pression évaluative en dépit du fait qu'ils sont sans doute parmi les moins aisément évaluables et mesurables dans leurs effets.

De ce point de vue, un piège nous guette, puissant, celui de l'instrumentalisation. Toutes les justifications que je viens d'énumérer sont fort louables à certains égards et il faut poursuivre les recherches et mieux comprendre, de façon plus objective, les impacts ou les effets de l'art en éducation et sur le développement social et cognitif de l'enfant. Mais il faut sans doute aussitôt rappeler que l'art a une valeur intransitive, qui ne doit servir ni les autres disciplines ni un supplément d'âme. L'art vaut pour lui-même parce qu'il engage une part essentielle de l'éducation, "l'intelligence sensible », diraient Alain Kerlan et Samia Langar, le « sensible comme forme de l'intelligible », l'art comme « expérience esthétique ", tout à la fois sensible, émotive, affective et intellectuelle. L'art se suffit à lui-même, il est à lui-même sa propre fin, c'est la grande leçon d'une riche tradition philosophique, à commencer par Aristote jusqu'à Hegel sans oublier Kant, et il ne donne sa pleine mesure éducative qu'en étant pleinement lui-même, c'est-à-dire pleinement art (Kerlan et Langar, 2015). J'en viens à mon deuxième ensemble de considérations, la formation des enseignants. 


\section{Formation des enseignants et rapport à la culture}

Je commencerai par une évidence : pas d'éducation artistique et culturelle à l'école, pas de vie propre, riche et créatrice, pour l'art et la culture à l'école sans enseignants cultivés et engagés. Après tout, c'est souvent à travers des personnes, notamment des enseignants, que nous rencontrons l'art et la culture. Car un enseignant ne fait pas que transmettre un savoir, il transmet un rapport au savoir; il ne fait pas que transmettre de la culture, mais un rapport à la culture, une manière de l'habiter. Des enseignants cultivés, c'est-à-dire ouverts, éveillés, curieux des choses de l'art et de la culture dans leur vie personnelle. Des enseignants engagés aussi, qui ont une passion communicative pour les arts et la culture, une passion qui provoque de vraies rencontres où l'art et la culture peuvent faire événement dans la vie de l'élève. Comment ne pas être d'accord? Et pourtant... s'il est une chose que j'ai apprise comme formateur d'enseignants, c'est que la relation entre l'enseignement et la culture n'a justement rien d'évident pour les futurs enseignants. Comment l'expliquer? Je risque une réponse qui mériterait une analyse plus étoffée.

Dans son dernier ouvrage La condition enseignante au Québec, Maurice Tardif montre bien que la professionnalisation de l'enseignement et de la formation à l'enseignement, ambition que nous poursuivons depuis déjà une bonne trentaine d'années au Québec et ailleurs, n'a pas eu d'effets notables sur le bassin social de recrutement des nouvelles générations d'enseignants. Celles et ceux qui se forment pour devenir des enseignants, celles et ceux qui sortent de nos universités présentement et celles et ceux qui arrivent proviennent en grande partie de la classe moyenne, de la classe moyenne inférieure, de familles ouvrières et de familles qui occupent des emplois techniques, des métiers de service et des emplois de bureau. En outre, on constate que plus de $70 \%$ des parents n'ont pas été à l'université et que près de 40 \% d'entre eux n'ont aucun diplôme d'études secondaires (Tardif, 2013, p. 291-292). Pour plusieurs de nos futurs enseignants, et considérant les enquêtes sur les pratiques culturelles, on peut penser qu'ils n'ont pas été véritablement en contact avec la culture et que l'accès à l'université représente une « rupture culturelle » par rapport à leurs milieux d'origine. C'est là une donnée sociologique qui n'est pas négligeable à mon avis et qui devrait entrer dans la réflexion des formateurs universitaires qui tiennent peut-être trop souvent pour acquis que le rapport à la culture des futurs enseignants est déjà bien constitué et pleinement favorable à la réalisation de la mission culturelle de l'école. Non seulement nous ne devrions pas le tenir pour acquis, mais nous devrions faire beaucoup plus, voir le prendre en charge et le développer de manière explicite en privilégiant des plans de formation qui pourraient comporter au moins cinq composantes : une réflexion approfondie sur son propre rapport à la culture; des expériences culturelles nombreuses et variées; une réflexion sur ces expériences pour en expliciter le sens; un accompagnement théorique pour soutenir cette réflexion et pour mieux comprendre les lignes de force et d'évolution de la culture dans laquelle nous vivons et les relations entre la différenciation sociale et les pratiques culturelles; un réinvestissement, enfin, dans la pratique pédagogique. De ce point de vue, la formation de passeurs culturels, comme on a l'habitude de le dire, est un enjeu de premier plan pour la mise en œuvre d'une éducation aux arts et à la culture à l'école.

Je voudrais finir par où j'ai commencé : le désir. C’est important le désir, c'est chose sérieuse que le désir, on ne confie pas son désir à n’importe qui. Pourquoi n'avons-nous plus envie de culture? Pourquoi ce flétrissement du désir de la culture au moment où nous pourrions réaliser le projet d'une éducation artistique pleinement démocratique? Je risquerais une réponse, une hypothèse. Pour avoir le désir de 
la culture, il faut avoir fait de vraies rencontres avec les artistes, les arts et la culture, des rencontres qui vous ébranlent, qui font événement dans votre vie, qui vous touchent et vous émeuvent, qui peuvent changer votre vie. Alors si j'étais ministre de la Culture, ma politique de la culture serait une politique du désir centrée sur l'expérience esthétique comme expérience de vérité (Gadamer, 1976), celle qui fait entrer l'art et la culture dans sa vie pour ne plus jamais en sortir.

Les enseignants, les arts et la culture... une connivence possible?

\section{Note}

1 L'emploi du masculin ne saurait être vu comme une marque de discrimination à l'égard des femmes.

\section{Références}

Gadamer, H.-G. (1976). Vérité et méthode. Paris : Seuil.

Kerlan, A. et Langar, S. (2015). Cet art qui éduque. Bruxelles : Fédération Wallonie-Bruxelles.

Simard, D. (2017, octobre). Ombre et lumière sur l'art et la culture à l'école et dans la classe. Communication présentée dans le cadre d'une journée de réflexion au Centre culturel de l'Université de Sherbrooke, « La culture à l'école. Pour quoi faire et comment? », Sherbrooke, QC.

Tardif, M. (2013). La condition enseignante au Québec du XIXe au XXI siècle. Une bistoire cousue de fils rouges : précarité, injustice et déclin de l'école publique. Québec, QC : Presses de l'Université Laval.

\section{Pour citer cet article}

Simard, D. (2018). Les enseignants, les arts et la culture : une connivence possible? Formation et profession, 26(1), 149-152. http://dx.doi.org/10.18162/fp.2018.a142 